\title{
Separation of Guanine and Hypoxanthine with Some Ionic Liquids in RP-HPLC
}

\author{
J. Zheng and K.H. Row \\ Center for Advanced Bioseparation Technology \\ Department of Chemical Engineering, Inha University, Incheon 402-751, South Korea
}

\begin{abstract}
In this paper, guanine and hypoxanthine were separated with four different ionic liquids as additives for the mobile phase using reversed phase high performance liquid chromatography (RPHPLC). The ionic liquids, 1-butyl-3-methylimidazolium tetrafluoroborate ([BMIm][BF $]$ ), 1-ethyl-3methylimidazolium tetrafluoroborate $\left([\mathrm{EMIm}]\left[\mathrm{BF}_{4}\right]\right)$, 1-ethyl-3-methylimidazolium methylsulfate ([EMIm][MS]) and 1-octyl-3-methylimidazolium methylsulfate ([OMIm][MS]) were used. Guanine and hypoxanthine couldn't be separated with many different kinds of unadjusted mobile phase, such as aqueous-methanol, aqueous-acetonitrile, etc. In this reason, present study introduced the ionic liquid for separation of guanine and hypoxanthine as an eluent modifier. And the effects of length of alkyl on the imidazolium ring and its counterion, the concentrations of ionic liquid on the retention factor and effect of $\mathrm{pH}$ of mobile phase on retention factor of solutes were investigated also. As a result, guanine and hypoxanthine were separated with the mobile phase including ionic liquid and the excellent separations of these sorbats were achieved using $2.0 \mathrm{mM} \mathrm{L}^{-1}$ [OMIm] [MS] as the eluent modifier.
\end{abstract}

Key words: RP-HPLC, ionic liquid, guanine, hypoxanthine, retention factor

\section{INTRODUCTION}

Room-temperature ionic liquids, salts that are liquids at ambient temperature, are normally composed of relatively large organic cations and inorganic or organic anions ${ }^{[1]}$. Unlike molecular liquids, ionic liquids are polar solvents and have some unique properties, such as negligible vapor pressure, good thermal stability, tunable viscosity and miscibility with water and organic solvents, as well as good extractability for various organic compounds and metal ions ${ }^{[2]}$. Because of these characteristic properties, ionic liquids have been used as a new solvent media in analytical chemistry ${ }^{[2]}$, catalysis ${ }^{[3,4]}$ and biocatalysis ${ }^{[5]}$, synthesis $^{[6]}$ and separation science ${ }^{[7-12]}$. Currently, scientists are interested in the applications of ionic liquids in separation and analysis, because, when ionic liquids are diluted or immobilized on a stationary support, they may not possess all the properties of the ordinary ionic liquids, in some cases, they may keep several kinds of intermolecular interactions ${ }^{[13]}$. Jiang and coworkers reported the ionic liquids as additives in eluents to separate ephedrines ${ }^{[7]}$ and catecholamines ${ }^{[14]}$ in high performance liquid chromatography (HPLC). Pool and coworkers studied the use of ethyl ammonium nitrate and propyl ammonium nitrate in liquid chromatography ${ }^{[15]}$.

Various enzyme defects in the metabolic pathways of purines and pyrimidines are known, which result in different diseases occurring in children. They mainly affect kidney function, central nervous system, immunological and blood systems. For example, complete deficiency of HPRT (hypoxanthine-guaninephosphoribosyl-transferase) causes the Lesch Nyhan syndrome, which is characterized by hyperuricemia, mental retardation, choreoathetosis and compulsive self-mutilation. XDH deficiency (xanthinedehydrogenase) causes in arthropathia and myopathia $^{[16]}$.

Purine and pyrimidine bases and their nucleotides participate in many critical cellular functions. Studies showed that hypouricemia and higher plasma levels of xanthine and hypoxanthine than as normal subjects occurred in patients suffering on xanthinuria. Furthermore, the daily urinary excretion of anthine and hypoxanthine was markedly increased compared with reference values of normal subjects ${ }^{[17]}$. The excretion of hypoxanthine and xanthine was not related to sex. Urinary oxypurines were related to age and, when corrected for body surface area, they were significantly higher in normal children under 15 years of age than in adults $^{[18]}$.

The purpose in present study is to investigate the potential application of different ionic liquids as additives for the separation of guanine and hypoxanthine. Four types of ionic liquids were used as mobile phase modifiers in reversed-phase HPLC (RPHPLC) to isolate the two-purine derivatives. The retention factors of the guanine and hypoxanthine were determined with mobile phase comprising with four ionic liquids in aqueous-methanol. The types of investigated ionic liquids and the name, structure of the sorbats were listed in Table 1 . We examined the effects of concentration of ionic liquids with their nature on the chromatographic retention and separation.

Corresponding Author: K.H. Row, Center for Advanced Bioseparation Technology, Department of Chemical Engineering, Inha University, Incheon 402-751, South Korea, Tel: +82-32-860-7470, Fax: +82-32-872-0959 


\section{MATERIALS AND METHODS}

Reagents: Four ionic liquids (99.99\%), such as 1-butyl3-methylimidazolium tetrafluoroborate ([BMIm] $\left.\left[\mathrm{BF}_{4}\right]\right)$, 1-ethyl-3-methylimidazolium tetrafluoroborate ([EMIm] $\left.\left[\mathrm{BF}_{4}\right]\right), \quad$ 1-ethyl-3-methylimidazolium methylsulfate ([EMIm][MS]) and 1-octyl-3methylimidazolium methylsulfate ([OMIm][MS]) were purchased from C-tri Co. (Namyang, Korea). Guanine and hypoxanthine were purchased from Tokyo Kasei Kogyo Co. Potassium nitrate $\left(\mathrm{KNO}_{3}\right)$ was purchased from Kanto Chemical Co. (Japan) to measure the dead volume. HPLC grade methanol $\left(\mathrm{CH}_{3} \mathrm{OH}\right)$ was purchased from Duksan Pure Chemical Co. (Ansan, Korea), buffer solution standard $\mathrm{pH} 4.0,7.0$ and 10.0 were from DC Chemical Co. (Japan). Distilled water was filtered with a vacuum pump (Division of Millipore, Waters, U.S.A.) and filter (HA-0.45, Division of Millipore, Waters, U.S.A.) before use.

Apparatus: The instruments used in this study were as follows: M930 solvent delivery pump (Young Lin Co.), UV detector (M 720 Absorbance Detector, Young-In Scientific Co.), a Reodyne injection valve with a $20 \mathrm{ml}$ sample roop and integrated data system (Autochrowin, Ver. 1.42, Young Lin Co.) The experiments were performed with the commercial available $\mathrm{C}_{18}$ (alkyl-) bonded phase column $(4.6 \times 150 \mathrm{~mm}$ i.d. and particle size $5 \mu \mathrm{m}$ ). $\mathrm{pH}$ meter (HANNA Co.) was calibrated with buffer solution standards $\mathrm{pH} 4.0,7.0$ and 10.0.

Chromatographic conditions: Stock solutions of the standards of $50 \mathrm{ppm}$ each were prepared by dissolving individual standards in pure water. Mixture was prepared as aliquots of individual solutions of guanine and hypoxanthine in the ratio of $6: 1$, respectively. Mobile phase was $40.0 \mathrm{vol}$. \% of methanol in water (pure reversed-phase system). Various systems $(0.5,1.0$ $\left.2.0,4.0 \mathrm{mM} \mathrm{L}^{-1}\right)$ of ionic liquids in eluent were used. Using $10 \%(\mathrm{v} / \mathrm{w})$ hydrochloric acid $(\mathrm{HCl})$ adjusted the pure reversed-phase system with 40.0 vol.\% of methanol and eluents containing different type and concentration of ionic liquids to $\mathrm{pH}$ 3.0. The flow rate was fixed at $1.0 \mathrm{~mL} \mathrm{~min} \mathrm{mi}^{-1}$ and performed on isocratic mode. A constant injection volume $(10 \mu \mathrm{L})$ was used throughout for the individual solution. The injection volume of mixture was $20 \mu \mathrm{L}$. Detection at wavelength was used $254 \mathrm{~nm}$. The solutions were stored at $4^{0} \mathrm{C}$ and the working standards were reprepared every 2 days to avoid the potential errors from decomposition of the targets. Retention factor $k$ were calculated using the formula

$$
k=\left(t_{R}-t_{0}\right) / t_{0}
$$

where $t_{R}$ is the retention time of the analyte and $t_{0}$ is the retention time of the non-retained peak (taken as the first deviation of the baseline following the injection of $10 \mu \mathrm{KNO}_{3}$ ). Three of replicated injections were made to determine the retention time and the average values were used to calculate the retention factors.

The resolution $\left(R_{s}\right)$ was calculated using the equation (2)
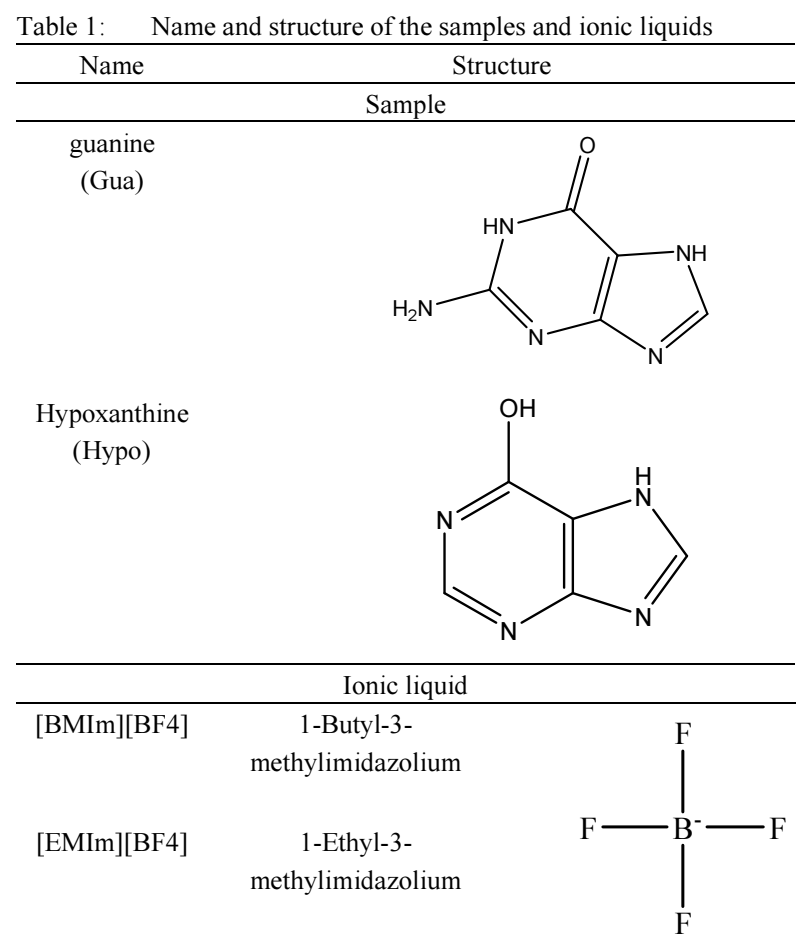

[EMIm][MS] 1-Ethyl-3-

methylimidazolium
[OMIm][MS] octylimidazolium

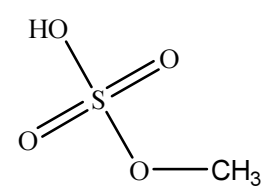

$R_{s}=\frac{t_{R 2}-t_{R 1}}{\left(w_{2}+w_{1}\right) / 2}=\frac{2 \Delta t}{w_{2}+w_{1}}$

where $t_{R 1}$ and $t_{R 2}$ was the retention times of the first and second peak $\left(t_{R 1 \leq} t_{R 2}\right)$, respectively and $w_{1}$ and $w_{2}$ was the peak widths of the first and second peak, respectively.

Evaluation of the results of the chromatographic experiment was carried out by mathematical statistic techniques. The relative error of a single measurement did not exceed at 5\%. All experimental procedures were performed at an ambient temperature.

\section{RESULTS AND DISCUSSION}

Optimum mobile phase condition for separation guanine and hypoxanthine: In the RP-HPLC, the parameters which affect the sorption of the substances onto the stationary phase and hence the retention of solutes include many effects, like the nature of the stationary phase, the lipophilicity of the substance, the concentration of the solute in the mobile phase, the ionic strength of the mobile phase, the nature-and concentration of any competing modifier added to the eluent. The strength of a mobile phase is defined by its 


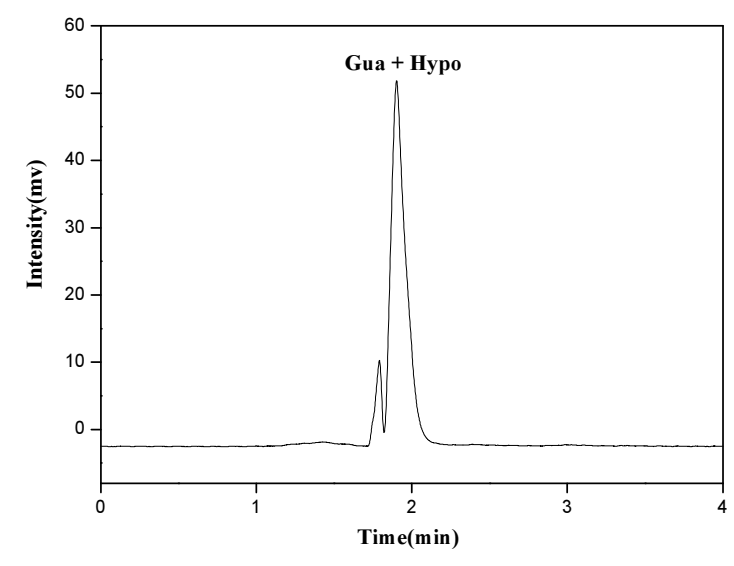

Fig. 1: Chromatograms of a mixture on mobile phase $(40 \% \mathrm{MeOH})$

polarity, thus the ability is to dissolve more polar compounds. Solvent selectivity, on the other hand, is the ability to dissolve compounds that have the same polarity. Each solvent will be shown a favorable kind of interaction with sample solutes that show the same polarity. The optimization of solvent strength and/or selectivity is a major goal in chromatographic method development.

Usually, retention time in RP-HPLC will increase as increasing the lipophilicity of the substance and as decreasing percentage of organic modifier in the mobile phase.

Guanine $(\log P=-1.27)$ and hypoxanthine $(\log P$ $=0.41$ ) have close values of octanol/water partition coefficient $(\log P)$ and it is one of basic reason in difficulty of their isolation with a pure reversed-phase system. The calculation of lipophilicity $(\log P)$ was performed using the Chem Office software ${ }^{[19]}$.

To investigate the chromatographic behavior of guanine and hypoxanthine with a pure reversed-phase system, many kinds of mobile phase (aqueous-methanol, aqueous-acetonitrile, aqueous-methanol with buffer etc) were tested as a preliminary. From these binary and ternary mobile phases, guanine and hypoxanthine couldn't be separated. Thus, we decide to use ionic liquid for a modifier adds into the aqueous-methanol (575 vol.\%). This experiment shows that from wide range of methanol concentrations, higher than 40 vol.\%, samples couldn't be identified due to elution of guanine with many peaks. Guanine and hypoxanthine couldn't be separated with lower than 40 vol.\% methanol also and lower than 40 vol.\% of methanol, the elution peaks were shown broadening. From these reasons, the eluent with 40 vol.\% of methanol was selected and indicated that in a pure reversed-phase system the separation couldn't achieve using methanol only as modifier of mobile phase as shown in Fig. 1.

Determination $\mathbf{p H}$ of mobile phases, which contains different types and concentrations of ionic liquids: To investigate the $\mathrm{pH}$ of mobile phase with containing different types and concentrations of ionic liquids, 0.5 $4.0 \mathrm{mM} \mathrm{L}^{-1}$ of ionic liquids were added in pure mobile phase as additives. $\mathrm{pH}$ of the original pure mobile phase (40 vol.\% of methanol in water) was 7.1 and after addition different concentrations of ionic liquids, $\mathrm{pH}$ were clearly changed. $\mathrm{pH}$ of mobile phase with containing $[\mathrm{BMIm}]\left[\mathrm{BF}_{4}\right]$ and $[\mathrm{EMIm}]\left[\mathrm{BF}_{4}\right]$ were slightly increased, the opposite, $\mathrm{pH}$ with [EMIm][MS] and $[\mathrm{OMIm}][\mathrm{MS}]$ were decreased with increasing the concentration of ionic liquids. This phenomenon can be probably determined by the structure of $\left[\mathrm{BF}_{4}\right]$ and $[\mathrm{MS}]$ anions of ionic liquids. From the structure of methylsulfate anion ([MS]), it is including the hydroxyl group. Thus, methylsulfate anion can donate the hydrogen cations easily, in other word, invests acidity. But tetrafluoroborate $\left(\left[\mathrm{BF}_{4}\right]\right)$ is weak basic anions. To select an optimal $\mathrm{pH}$, the resolution is evaluated by changing $\mathrm{pH}$ values of the mobile phase. The $\mathrm{pH}$ of the mobile phase was adjusted with $10 \%$ (v/w) hydrochloric acid solution. Because guanine contain amino group, so it is commonly easy to tail off on a $\mathrm{C}_{18}$

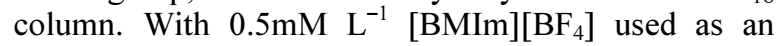
additive, when $\mathrm{pH}$ values were adjusted with $10 \%(\mathrm{v} / \mathrm{w})$ hydrochloric acid solution to $3.0,4.0,5.0$ and 6.0 , the resolutions of sorbets were decreased greatly from 1.34 to 0 . So $\mathrm{pH}$ value of all mobile phase was adjusted to 3.0 .

Effect of ionic liquids concentrations on retention of guanine and hypoxanthine: As reported by other authors $^{[1,13]}$, the ionic liquid cations in the eluent will adsorb onto the $\mathrm{C}_{18}$ silica based surface and cause changes in their properties. Imidazolium cations can interact with silanol groups and compete with the polar group of analytes for the silanol groups on the alkylsilica surface in a column. Therefore, it can effectively shield residual silanols and improve the peak shapes, while also decreasing the retention time of the analytes. Another application of ionic liquid in chromatography is also for the suppression of deleterious effects of free silanols by using imidazolium tetrafluoroborate ionic liquid ${ }^{[14]}$. Addition of imidazolium tetrafluoroborate ionic liquid to mobile phases at concentrations of $0.5-1.5$ vol.\% as silanolblocking additives was markedly more efficient than that as the standard mobile phase additives, such as triethylamine and dimethyloctylamine.

The alkyl-imidazolium cations are UV-active. Its maximum absorbance wavelength was measured to be at. $212 \mathrm{~nm}$, the absorbance at $254 \mathrm{~nm}$ (the detection wavelength in this experiment) from the spectrum was so low compared to the maximum that it could be ignored.

In the next step, the influence of the ionic liquids concentration in the series $0.5-4.0 \mathrm{mM} \mathrm{L}^{-1}$ was tested. It is important to note here that after each experiment with the certain concentration of the ionic liquid and before the experiment with the subsequent concentration of the ionic liquid, the column was flushed for at least 3 hours to remove the ionic liquid used at previous concentration and/or to fully equilibrate the column. 

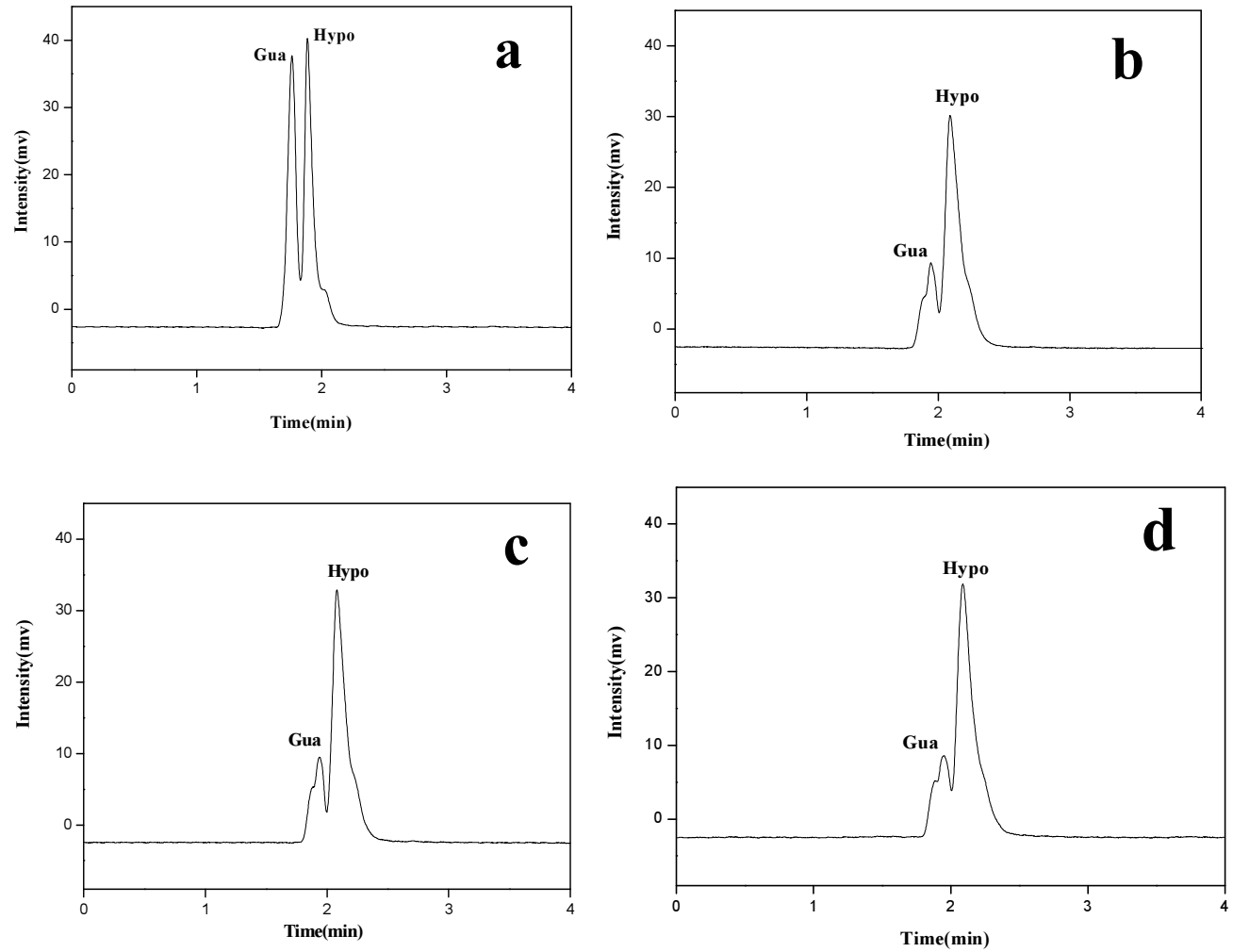

Fig. 2: Chromatograms of a mixture on mobile phase $(40 \% \mathrm{MeOH}, \mathrm{pH}=3.0)$ with concentrations of [BMIm] [BF 4 , a: $0.5 \mathrm{mM} \mathrm{L}^{-1}, \mathrm{~b}_{1}: 1.0 \mathrm{mM} \mathrm{L}^{-1}$, c: $2.0 \mathrm{mM} \mathrm{L}^{-1}, \mathrm{~d}: 4.0 \mathrm{mM} \mathrm{L}^{-1}$
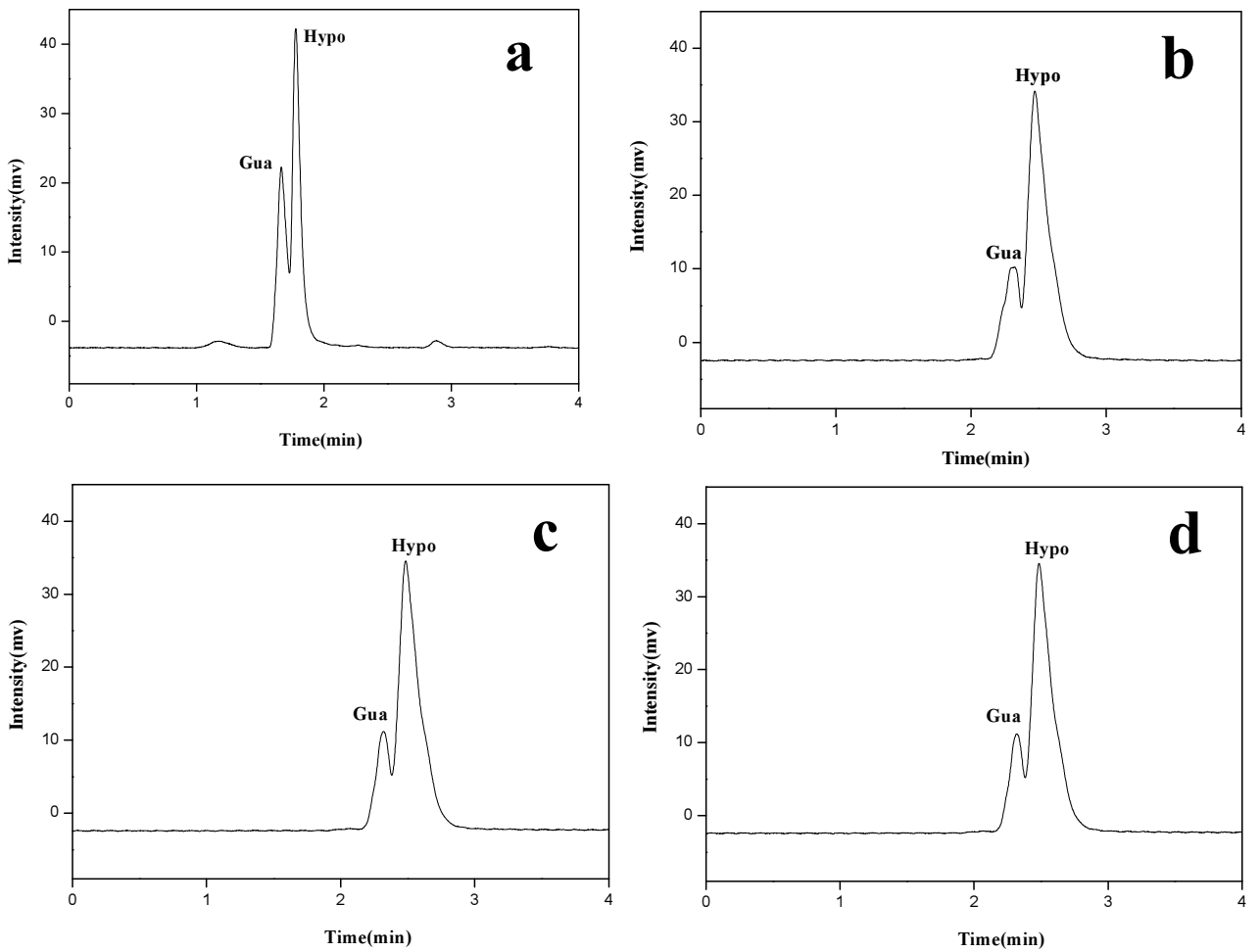

Fig. 3: Chromatograms of a mixture on mobile phase $(40 \% \mathrm{MeOH}, \mathrm{pH}=3.0)$ with concentrations of [EMIm] $\left[\mathrm{BF}_{4}\right]$, a: $0.5 \mathrm{mM} \mathrm{L}^{-1}, \mathrm{~b}: 1.0 \mathrm{mM} \mathrm{L}^{-1}$, c: $2.0 \mathrm{mM} \mathrm{L}^{-1}, \mathrm{~d}: 4.0 \mathrm{mM} \mathrm{L}^{-1}$ 
Am. J. Appl. Sci., 3 (12): 2160-2166, 2006
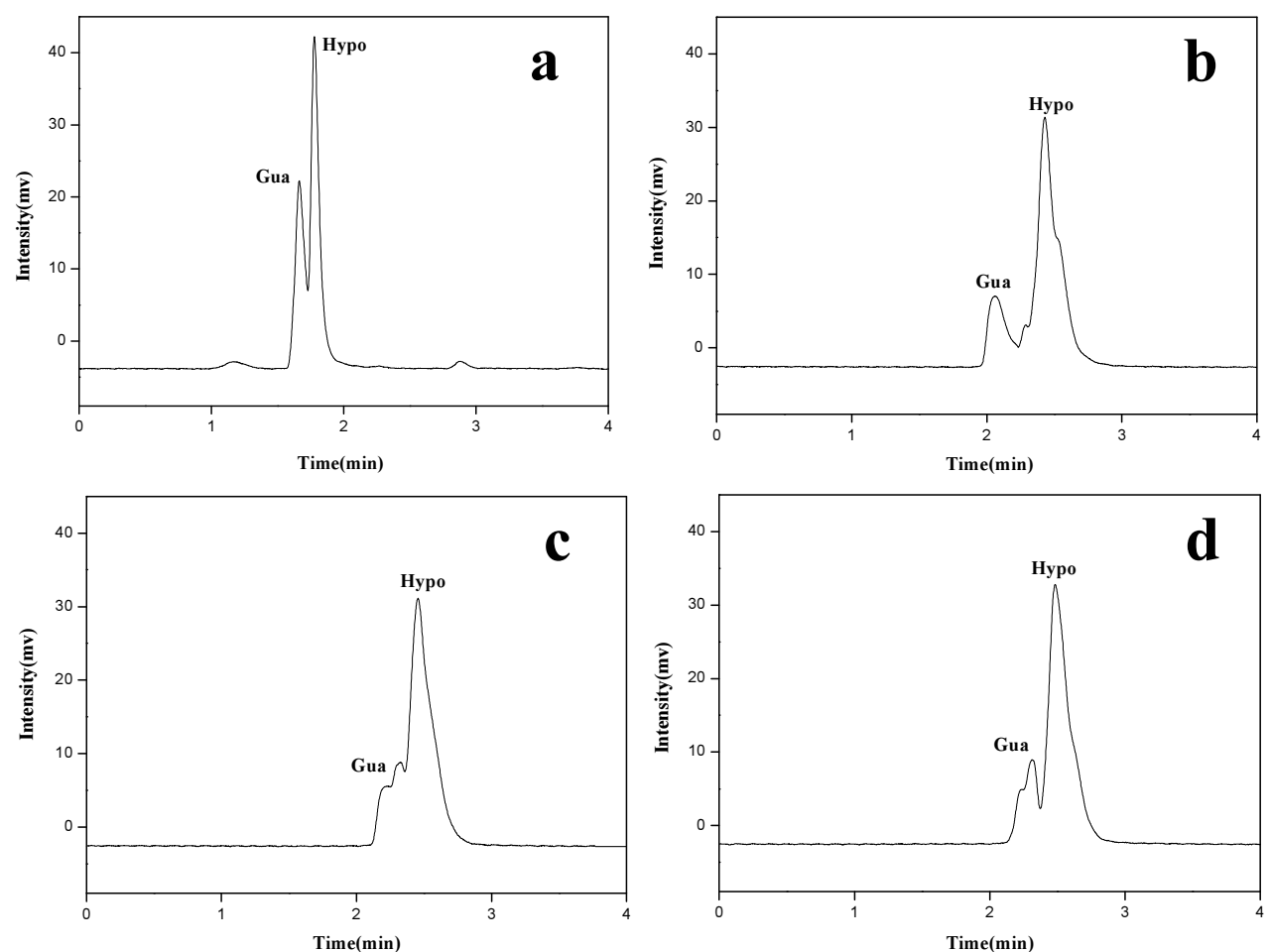

Fig. 4: Chromatograms of a mixture on mobile phase $(40 \% \mathrm{MeOH}, \mathrm{pH}=3.0)$ with concentrations of [EMIm] [MS], a: $0.5 \mathrm{mM} \mathrm{L}^{-1}, \mathrm{~b}: 1.0 \mathrm{mM} \mathrm{L}^{-1}$, c: $2.0 \mathrm{mM} \mathrm{L}^{-1}, \mathrm{~d}: 4.0 \mathrm{mM} \mathrm{L}^{-1}$
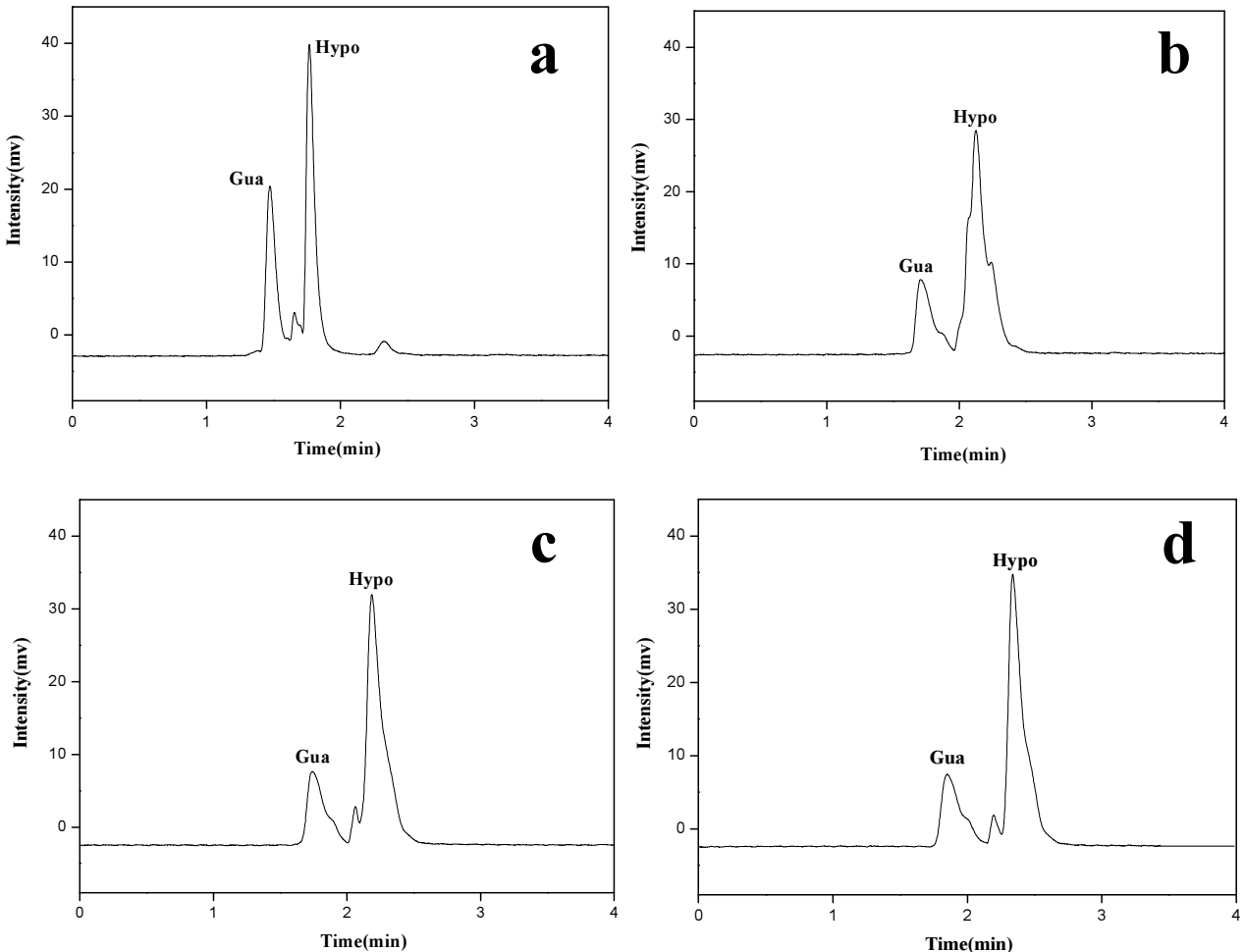

Fig. 5: Chromatograms of a mixture on mobile phase $(40 \% \mathrm{MeOH}, \mathrm{pH}=3.0)$ with concentration of [OMIm][MS], a: $0.5 \mathrm{mM} \mathrm{L}^{-1}, \mathrm{~b}: 1.0 \mathrm{mM} \mathrm{L}^{-1}$, c: $2.0 \mathrm{mM} \mathrm{L}^{-1}, \mathrm{~d}: 4.0 \mathrm{mM} \mathrm{L}^{-1}$ 
Table 2: Retention factors of guanine and hypoxanthin with different ionic liquids and concentrations

\begin{tabular}{|c|c|c|c|c|c|c|c|c|}
\hline \multirow[b]{3}{*}{ Conc. } & \multicolumn{8}{|l|}{ Type } \\
\hline & \multicolumn{2}{|c|}{ [BMIm][BF4] } & \multicolumn{2}{|c|}{ [EMIm][BF4] } & \multicolumn{2}{|c|}{ [EMIm][MS] } & \multicolumn{2}{|c|}{ [OMIm][MS] } \\
\hline & guanine & hypoxanthine & guanine & hypoxanthine & guanine & hypoxanthine & guanine & hypoxanthine \\
\hline $0.5 \mathrm{mM}$ & 0.10 & 0.18 & 0.04 & 0.11 & 0.10 & 0.18 & 0.02 & 0.11 \\
\hline $1.0 \mathrm{mM}$ & 0.21 & 0.31 & 0.45 & 0.55 & 0.29 & 0.52 & 0.07 & 0.33 \\
\hline $2.0 \mathrm{mM}$ & 0.21 & 0.30 & 0.45 & 0.55 & 0.38 & 0.53 & 0.09 & 0.37 \\
\hline $4.0 \mathrm{mM}$ & 0.22 & 0.31 & 0.45 & 0.56 & 0.45 & 0.55 & 0.16 & 0.46 \\
\hline
\end{tabular}

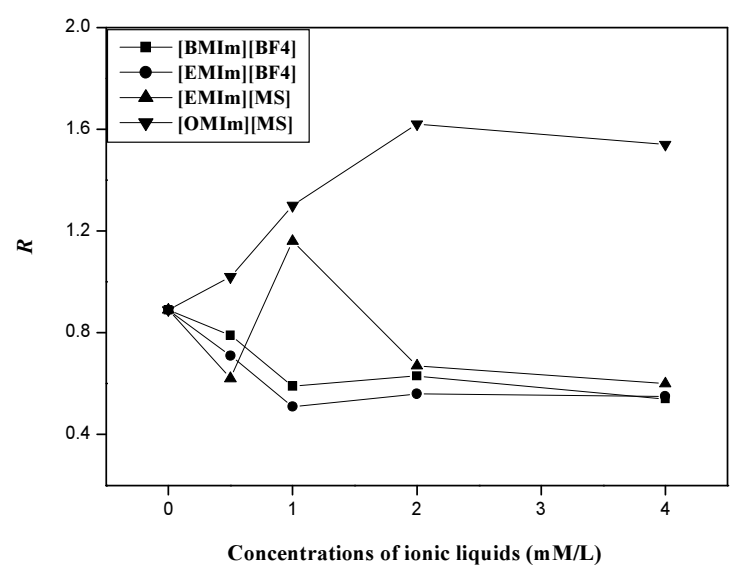

Fig. 6: Resolution of hypoxanthine and guanine with contents of four ionic liquids

The constancy in efficiency and peak tail factor showed that the use of ionic liquids is not harmful to the column. In order to test the possible effects of ionic liquid on $\mathrm{C}_{18}$ (alkyl-) bonded phase, the column was evaluated before and after exposure to ionic liquid, using aqueous-methanol media as the mobile phase with the solutes.

Concentration of ionic liquids remarkably affects the retention and separation of the analytes. It is shown in Fig. 1 that the chromatogram of a mixture on pure mobile phase $(40 \% \mathrm{MeOH})$, guanine and hypoxanthine were not separated without any modifier. Figure 2-5 were shown results with different concentration of ionic liquids (the $\mathrm{pH}$ of mobile phase was adjusted 3.0). From these figures, we can see that the resolution of the guanine and hypoxanthine are no change if adding more than $0.5 \mathrm{mM} \mathrm{L}^{-1}$ of ionic liquids. And it is interesting to note that without ionic liquids, the peaks of guanine and hypoxanthine are completely overlapped (data was not present here), whereas after the addition of ionic liquids to eluent these solutes are partially or completely resolved.

Figure 6 was shown the resolution of the mixture of guanine and hypoxanthine on $40 \mathrm{vol} \% \%$ of methanol with $0.5 \sim 4.0 \mathrm{mM} \mathrm{L}^{-1}$ of different ionic liquids. Table 2 shows the retention factors of guanine and hypoxanthine with different ionic liquids and their concentrations. The effect of different alkyl groups on imidazolium cations was discussed in terms of obtained results. Addition of the $0.5 \mathrm{mM} \mathrm{L}^{-1}$ of ionic liquids with different alkyl groups ([BMIm] and [EMIm]) and same anion $\left[\mathrm{BF}_{4}\right]$ was used to separation of guanine and hypoxanthine, it is apparent that [BMIm] $\left[\mathrm{BF}_{4}\right]$ provides the better resolution. In comparison with a pure reversed-phase system (in our case is watermethanol systems), these ionic liquids improve significantly the peak shape, decrease the peak tailing and increase resolution - the reason may be that, [BMIm] $\left[\mathrm{BF}_{4}\right]$ and $[\mathrm{EMIm}]\left[\mathrm{BF}_{4}\right]$ shield the residual silanols. It seems that $[\mathrm{BMIm}]\left[\mathrm{BF}_{4}\right]$ is most effective in shielding residual silanols - perhaps this is the reason why the peak forms and resolutions improve with the increase in alkyl chain length.

In comparison with $[\mathrm{EMIm}]\left[\mathrm{BF}_{4}\right]$ and [EMIm][MS] as modifier, the hypoxanthine have very similar retention, but longer retention time for guanine

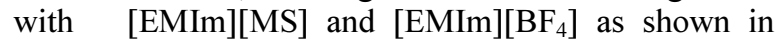
Table 2. The guanine have the peak broadening phenomena with [EMIm][MS]. The different separations that resulted from two ionic liquids with different counterions as the modifier may be due to the association with solutes at water-methanol media and it seems that [EMIm] with [MS] is superior to that with $\left[\mathrm{BF}_{4}\right]$ in the separation of guanine and hypoxanthine. The increase of the [MS] anion concentrations of ionic liquids in the eluents causes increase retention of all sorbets opposite with the $\left[\mathrm{BF}_{4}\right]$ anion. The mechanism of such effects is not clear at this time. Nonetheless, the contributions of the counterion to solute retention are presently under investigation.

We investigated the ionic liquid effects only 0.5 $4.0 \mathrm{mM} \mathrm{L}^{-1}$, because increasing the ionic liquid concentration in the mobile phase from $4.0 \mathrm{mM} \mathrm{L}^{-1}$, the elution phenomena were very similar with including $4 \mathrm{mM} \mathrm{L}^{-1}$ of each ionic liquids.

Excellent separation of guanine and hypoxanthine is achieved at the concentration $2.0 \mathrm{mM} \mathrm{L}^{-1}$ of [OMIm][MS]. But with a further increase the concentration of four different ionic liquids, guanine will have very broad peak and the resolution of guanine and hypoxanthine slowly decreases to zero.

\section{CONCLUSION}

In this paper, we discussed the effects of four ionic liquids for separation of guanine and hypoxanthine. The length of alkyl on the imidazolium ring and its 
counterion, the concentrations of ionic liquids can also affect the separation regularly. According to these results, we suppose that there would be complex mechanisms when ionic liquids are used as additives in HPLC and strong interactions between the imidazolium cation and its counterion of ionic liquids and solutes would also play important roles. Part of ionic liquids coat on the surface of the stationary phase, on which they suppress free silanols and improve the shape of peaks and resolution. As a result, excellent separation of guanine and hypoxanthine with ionic liquids was achieved using $2.0 \mathrm{mM} \mathrm{L}^{-1}$ [OMIm][MS ] as the modifier with adjusted $\mathrm{pH}$ of eluents to 3.0. The role of ionic liquids is multiplex and further research is needed in order to explain some of the phenomena. In any case, ionic liquids showed promising performance as an additive in HPLC.

\section{ACKNOWLEDGEMENT}

The authors are grateful for the financial support of the Center for Advanced Bioseparation Technology, Inha University.

\section{REFERENCES}

1. Xiao, X., Z. Liang, L. Xia and S, Jiang, 2004. Ionic liquids as additives in high performance liquid chromatography analysis of amines and the interaction mechanism of ionic liquids. Anal. Chim. Acta., 519: 207-211.

2. Liu, J., J. Jonsson and G. Jiang, 2005. Application of ionic liquids in analytical chemistry. TrAC Trend Anal. Chem., 24: 20-27.

3. Zhao, D., M. Wu and Y. Kou, 2002. Min. Ionic liquids: applications in catalysis. Catal. Today, 74: 157-189.

4. Gordon, C.M., 2001. New developments in catalysis using ionic liquids. Appl. Catal. A, 222: 101-117.

5. Yang, Z. and W. Pan, 2005. Ionic liquids: Green solvents for nonaqueous biocatalysis. Enzyme Microb. Technol., 37: 19-28.

6. Sun, J., S. Fujita and M. Arai, 2005. Development in the green synthesis of cyclic carbonate from carbon dioxide using ionic liquids. J. Organomet. Chem. (In Press).

7. He, L., W. Zhang, L. Zhao, X. Liu and S.X. Jiang, 2003. Effect of 1-alkyl-3-methylimidazoliumbased ionic liquids as the eluent on the separation of ephedrines by liquid chromatography. J. Chromatogr. A, 1007: 39-45.
8. Polyakova, Y., Y. Jin, J. Zheng, K.H. Row, 2006. Effect of concentration of ionic liquid 1-butyl-3methylimidazolium tetrafuoroborate for retention and separation of some amino and nucleic acids. J. Liq. Chromatogr. Related Technol., 29: 1687-1701.

9. Marszałł, M.P., T.B aczek and R. Kaliszan, 2005. Reduction of silanophilic interactions in liquid chromatography with the use of ionic liquids. Anal. Chim. Acta., 547: 172-178.

10. Waichigo, M.M., T.L. Riechel and N.D. Danielson, 2004. Ethylammonium acetate as mobile phase modifier for reversed phase liquid chromatography. Chromatogr., 61: 17-23.

11. Zhang, W., L.J. He, L. Xia and S.X. Jiang, 2004. Ionic liquids as mobile phase additives for separation of nucleotides in HPLC. Chin. J. Chem., 22: 549-552.

12. Lee, C.H., J.W. Lee and K.H. Row, 1998. Optimum solvent selectivity and gradient mode for deoxyribonucleosides in reversed-phase highperformance liquid chromatography. J. Chromatogr. A, 1072: 337-344.

13. Polyakova, Y., Y. M. Koo and K. H. Row, 2006. Application of ionic liquids as mobile phase modifier in HPLC. Biotechnol. Bioprocess Eng., 11: 1-6.

14. Zhang, W., L. He, Y. Gu, X. Liu and S. Jiang, 2003. Effect of ionic liquids as mobile phase additives on retention of catecholamines in reversed-phase highperformance liquid chromatography. Anal. Lett., 36: 827-838.

15. Prabhakara H.S., P.J. Youngberg, B.R. Kersten and C.F. Poole, 1987. Solvent properties of liquid organic salts used as mobile phases in microcolumn reversed-phase liquid chromatography. J. Chromatogr., 411: 61-79.

16. Vidotto, C., D. Fousert, M. Akkermann, A. Griesmacher and M.M. Müller, 2003. Purine and pyrimidine metabolites in children's urine. Clinica Chimica Acta, 335: 27-32.

17. Vannoni, D., B. Porcelli, R. Leoncini, L. Terzuoli, M. Pizzichini and D. Stefan et al., 1989. The excretion of oxypurines in normal subjects. Biomed. Pharmacother, 43: 513- 7.

18. Stapelton, F.B., M.A. Linshaw, K. Hassanein, A.B. Gruskin, 1978. Uric acid excretion in normal children. J. Pediatr; 92: 911-914.

19. Strack, D., 2001. ChemOffice Ultra 2000 CambridgeSoft. Phytochemistry, 57: 143-144. 